\title{
My mentors in urogynecology
}

\author{
Peter L. Dwyer ${ }^{1}$
}

Received: 19 September 2016 / Accepted: 19 September 2016/Published online: 13 October 2016

(C) The International Urogynecological Association 2016

If I see further it is only by standing on the shoulders of giants.

Sir Isaac Newton (1642-1727), discoverer of the Laws of Gravity.

Five years ago Paul Riss and I started a new section in the International Urogynecology Journal titled "Mentors in Urogynecology." We invited distinguished clinicians to write about their teachers, the people who introduced them to our subspecialty, taught them their clinical, surgical, and research skills, and gave them values in integrity and personal relationships to enable them to fulfill their own ambitions in medicine and in life.

As I am approaching the end of my term as Editor in Chief, I thought it appropriate to acknowledge those people who set my compass and gave me the skills I have in urogynecology. I will do this in the chronological order of their influence. My first major influence in urogynecology was Stuart Stanton. Linda Cardozo has already written on his influence on her career, but Stuart made major contributions to urogynecology and affected the careers of many UK and international urogynecologists. I was lucky to get a fellow's position in urogynecology in 1983 after spending a 3-week study leave in his department. I would recommend unpaid observerships to any aspiring young urogynecologists, as it gets you known so you will be in line for any permanent positions that become

Peter L. Dwyer

peter@pldwyer.com

1 Department of Obstetrics and Gynaecology, Mercy Hospital for Women, University of Melbourne, Melbourne, VIC, Australia available. Work with top people in the best departments is never easy to either to obtain or do, but always provides invaluable lessons for life and in medicine.

Stuart Stanton provided with his research a scientific basis for performing surgery to treat pelvic floor disorders. He and his team carried out many studies on pelvic floor dysfunction. Many were prospective randomized comparisons using objective measures to assess procedures in stress urinary incontinence and prolapse; a rarity in any surgical disciple in the 1970s and 1980s. Stuart was the first to carry out an RCT comparing anterior vaginal colporrhaphy and Burch colposuspension [1]. His studies established the place of the Burch colposuspension as the gold standard during the 1980s and 1990s [1]. Before this, most stress incontinence studies were retrospective reviews of personal, operator-assessed series, unsurprisingly reporting very high success rates. Stuart was always open to new ideas and research, even from the most junior members. He had what my former boss Norman Beischer called "a big engine" and usually took on many projects and then famously was capable of working through the night to finish them. He showed me how to set up a multidisciplinary urogynecology team, and by leading from the front set standards in research, writing, and patient care that were not only pertinent in his unit, but also set the bar internationally. Stuart is alive and well in London and still young at heart, but complains he is missing his patients in retirement (Fig. 1).

On returning to Australia from England in 1984, I worked with Robert Zacharin (Fig. 2) and Peter Glenning. Bob made a significant contribution to urogynecology. He described the anatomical supports of the urethra and their importance in the continence mechanism [2]. He told me that he found most of the important anatomical structures in the first hour in the anatomy laboratory. He published his findings in 1968 [2], the 


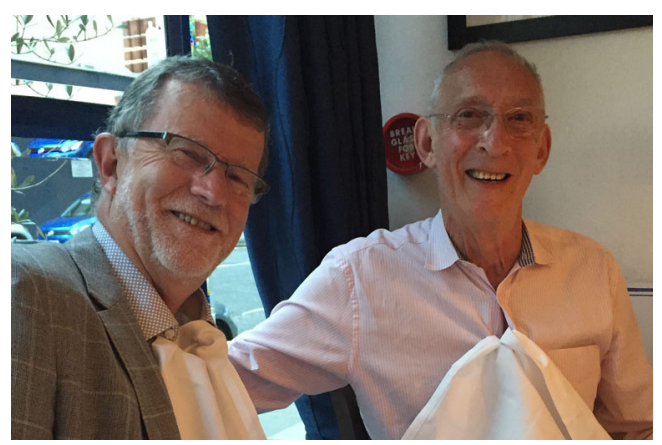

Fig. 1 Stuart Stanton and Peter Dwyer, London, 2016

year I started in medicine, and in a book entitled "Stress Incontinence of Urine" in 1972. I had the great opportunity to assist Bob surgically during the latter years of his career. Bob was a master surgeon who travelled extensively demonstrating his procedures. He used this knowledge of anatomy to surgically treat stress incontinence with a procedure that he called abdomino-perineal urethral suspension [3]. Through a low transverse abdominal incision, he fashioned two strips of rectus fascia, which he placed through the vagina using a special carrier device at the site of the insertion of the pubourethral ligaments. These fascial strips were sutured into position to support the urethra without tension. Peter Petros has acknowledged that he and Ulf Ulmsten based their operation, the tension-free vaginal sling (TVT), on Bob's anatomical studies and procedure. His work in vaginal prolapse was also extensive, describing anatomy and his own operation for recurrent enterocele and apical prolapse in a monograph entitled "Pelvic Floor Anatomy and the Surgery of Pulsion Enterocele" [4]. Using an abdominal and a vaginal approach,

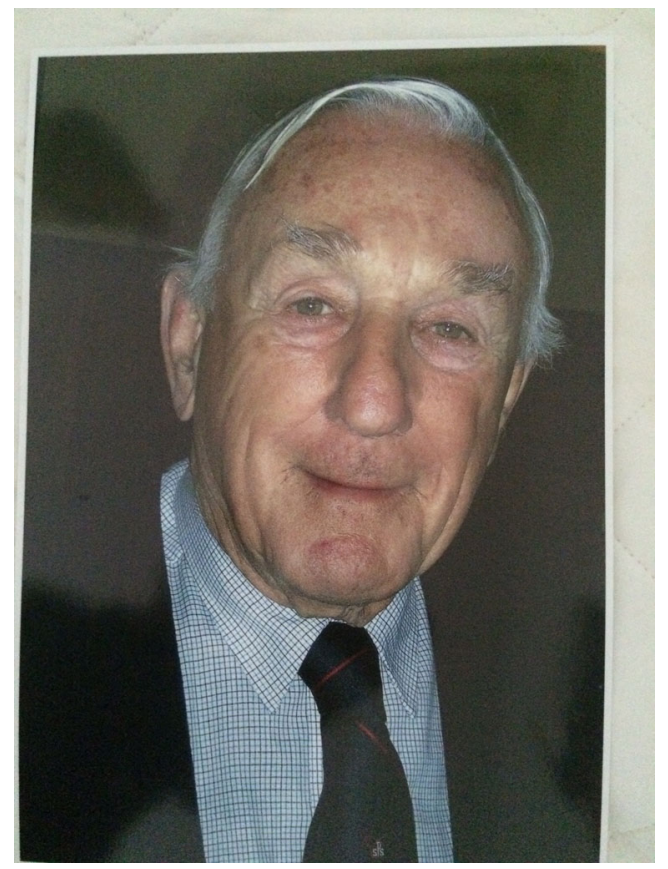

Fig. 2 Robert F Zacharin

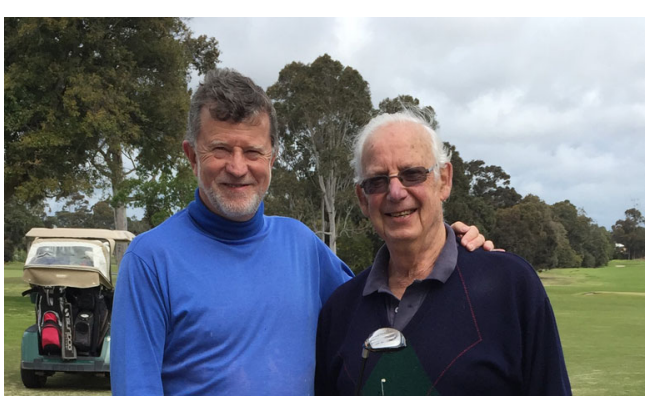

Fig. 3 Peter P Glenning

he closed the levator hiatus from above with interrupted sutures and suspended the vagina from above onto the levator plate. Later in his career, he used polypropylene mesh to reinforce his repair. His other surgical love was repairing vesicovaginal fistulae, in which he had gained extensive experience in Australia and from working with Reginald and Catherine Hamlin in Ethiopia. He wrote a book on his experience and the surgical correction in "Obstetric Fistulae," which he said should have been written by the Hamlins. He was a great original thinker and innovator in urogynecology and always excellent company; he sadly died in Melbourne in May 2012.

Peter Glenning (Fig. 3) was the first to set up and run a specialized urogynecology unit in Australia to investigate and treat women with urinary incontinence and other pelvic floor problems in 1970. He invited me to join his department at the Royal Women's Hospital in Melbourne and we worked together for many happy years until his retirement. He was an excellent clinician and surgeon, performing surgery across the range, including radical gyneco-oncological surgery and pelvic floor reconstruction. He is a gentle man, wise in his advice in medicine and in life generally. He, together with Jim Gibson from Sydney, established the subspecialty of urogynecology in Australia in the late 1980s, well before this occurred anywhere else. We still play golf together; thus, his mentoring continues to this day.

Finally, the acquisition of knowledge and wisdom never stops. I find I learn new things every day, not only from my colleagues and fellows, but also from my patients. They have taught me to be conservative in my treatment whenever possible, to try to do more good than harm, and that why you are operating is just as important as how you operate.

\section{References}

1. Stanton SL, Cardozo LD. A comparison of vaginal and suprapubic surgery in the correction of incontinence due to urethral sphincter incompetence. Br J Urol. 1979;51(6):497-9.

2. Zacharin RF. The anatomic supports of the female urethra. Obstet Gynecol. 1968;32(6):754-9.

3. Zacharin RF, Gleadell LW. A modified technique for abdominoperineal urethral suspension. Am J Obstet Gynecol. 1963;87:948-50.

4. Zacharin RF, Hamilton NT. Pulsion enterocele: long-term results of an abdominoperineal technique. Obstet Gynecol. 1980;55(2):141-8. 